\title{
Simplified Fuzzy Control for Flux-Weakening Speed Control of IPMSM Drive
}

\author{
M. J. Hossain, ${ }^{1}$ M. A. Hoque, ${ }^{2}$ and K. K. Islam ${ }^{2}$ \\ ${ }^{1}$ School of ITEE, The University of Queensland, Brisbane, QLD 4072, Australia \\ ${ }^{2}$ Islamic University of Technology, Dhaka, Gazipur 1704, Bangladesh \\ Correspondence should be addressed to M. J. Hossain, m.hossain9@uq.edu.au
}

Received 28 April 2011; Accepted 10 May 2011

Academic Editor: Salvatore Sessa

Copyright ( $) 2011$ M. J. Hossain et al. This is an open access article distributed under the Creative Commons Attribution License, which permits unrestricted use, distribution, and reproduction in any medium, provided the original work is properly cited.

\begin{abstract}
This paper presents a simplified fuzzy logic-based speed control scheme of an interior permanent magnet synchronous motor (IPMSM) above the base speed using a flux-weakening method. In this work, nonlinear expressions of $d$-axis and $q$-axis currents of the IPMSM have been derived and subsequently incorporated in the control algorithm for the practical purpose in order to implement fuzzy-based flux-weakening strategy to operate the motor above the base speed. The fundamentals of fuzzy logic algorithms as related to motor control applications are also illustrated. A simplified fuzzy speed controller (FLC) for the IPMSM drive has been designed and incorporated in the drive system to maintain high performance standards. The efficacy of the proposed simplified FLC-based IPMSM drive is verified by simulation at various dynamic operating conditions. The simplified FLC is found to be robust and efficient. Laboratory test results of proportional integral (PI) controller-based IPMSM drive have been compared with the simulated results of fuzzy controller-based flux-weakening IPMSM drive system.
\end{abstract}

\section{Introduction}

In recent years, the IPMSM has become increasingly popular for its use in high performance drive (HPD) applications due to desirable features, such as high torque to current ratio, high power to weight ratio, high efficiency, low noise, and robust operation. The advantageous features of the IPMSM for modern drives application are well established $[1,2]$. Fast and accurate speed response, quick recovery of speed from any disturbance, and insensitivity to parameter variations are some of the important criteria for HPD systems. These HPDs are used in robotics, rolling mills, machine tools, and so forth. The conventional proportional-integral (PI) and proportional-integral-derivative (PID) controllers have been widely utilized as speed controller in flux-weakening region in IPMSM drive [3]. However, difficulties in obtaining the exact $d-q$ axis reactance parameters of the IPMSM make the design approaches for these controllers cumbersome. Moreover, since the operation of the IPMSM is strongly affected by the rotor magnetic saliency, saturation, and armature reaction effects [2], conventional fixed-gain PI and PID controllers are very sensitive to parameter variations, along with step change of command speed, and load disturbance [4-6]. Therefore, an intelligent speed controller demands special attention for the IPMSM drives, which are used in HPD systems.

In an FLC, the system control parameters are adjusted by a fuzzy rule-based system, which is a logical model of the human behavior for process control. The advantages of FLC over the conventional controllers are as follows (1) the design of FLC does not need the exact mathematical model of the system; (2) the FLC is more robust than the conventional controllers; (3) it can handle nonlinear functions of any arbitrary complexity; (4) it is based on the linguistic control rules, which are also the basis of human logic. Many researches have been carried out with the fuzzy algorithms for ac (alternating current) motors drives [512]. These works are limited to the cases where the fluxweakening mode of operation is not considered. Researchers have focused their attention on the vector control of IPMSM drive by forcing the $d$-axis current equal to zero, which essentially linearizes the motor model for speed control up to the base speed $[13,14]$. There exists a need to extend the fuzzy logic-based control to the practical case IPMSM drive 
in the flux-weakening region where the IPMSM operates above the base speed. Recently, researchers have turned their attention to the flux-weakening control of IPMSM drives [10-12].

The IPMSM drive operation with vector control scheme strategy is well established [15]. However, the vector control techniques used in IPMSM drives become complicated due to the nonlinearity of the developed torque for nonzero value of $d$-axis current. In real time, the electromagnetic torque and the flux producing $d$-axis current are nonlinear in nature and the generated or back emf (electromotive force) of an IPMSM is directly proportional to the rotor speed. As the rotor speed increases, the back emf increases in the linear fashion since excitation flux is constant due to the permanent magnets. Thus, to reach a desired speed, the terminal voltage must be increased to overcome the back emf. It is the real-time practice that the inverter should be capable of supplying the required voltage by PWM or any other suitable techniques up to the base or rated speed. For the drive operation above the base speed, an indirect flux control method of field-weakening method can be applied to the drive, so that the terminal voltage will remain constant after the base speed. This flux- or field-weakening strategy is very important from the limitation of IPMSM and inverter rating points of view, which optimizes the drive efficiency. However, owing to the permanent magnet construction of the rotor, nothing can be done on the rotor side from the control point of view. It is possible to weaken the field by controlling the stator current in such a way that a direct axis current component in the rotating frame axis can be generated which will oppose the main field produced by the permanent magnet.

The problem with the associated flux-weakening control technique is that its implementation in real time becomes complicated because there exists a complex nonlinear relationship between $d$-axis current and speed and also among $d$ - and $q$-axis currents. Some researchers solved this problem by considering look-up table [3]. In this work, these nonlinearties are incorporated in the IPMSM drive system with a simpler expression of $d$-axis and $q$-axis current above the base speed using PI and fuzzy logic controller. The simplified expressions of $d$-axis and $q$-axis currents have been derived using curve fitting method and used in the simulation as well as real-time implementation. The objective of this paper is to present a simplified FLC-based speed controller for the IPMSM drive. The system is designed in such as way as to maintain the high performance drives employing a less complex algorithm of FLC, which reduces the computational burden and allows for real-time implementation above base speed. The proposed IPMSM drive system has been simulated using MATLAB/SIMULINK. Results of PI controller-based IPMSM drive have been compared with those obtained from the FLC-based IPMSM drive. The comparisons confirm the efficacy of the proposed system using FLC-based IPMSM drive system.

The organization of the paper is as follows: Section 2 provides the mathematical modeling of the IPMSM; flux weakening control algorithm is presented in Section 3; Section 4 describes the simplified fuzzy logic control design technique; Section 5 discusses the laboratory implementation of PI-based flux-weakening IPMSM drive; Section 6 presents the performance of the controller through a series of nonlinear simulation results. Concluding remarks and suggestions for future works are given in Section 7.

\section{IPMSM Dynamics}

The mathematical model of an IPMSM drive can be described by the following equations in a synchronously rotating rotor $d-q$ reference frame as:

$$
\begin{gathered}
{\left[\begin{array}{c}
v_{d} \\
v_{q}
\end{array}\right]=\left[\begin{array}{cc}
R+p L_{d} & -P \omega_{r} L_{q} \\
P \omega_{r} L_{d} & R+p L_{q}
\end{array}\right]\left[\begin{array}{l}
i_{d} \\
i_{q}
\end{array}\right]+\left[\begin{array}{c}
0 \\
P \omega_{r} \psi_{f}
\end{array}\right],} \\
T_{e}=T_{L}+J_{m} p \omega_{r}+B_{m} \omega_{r} \\
T_{e}=\frac{3 P}{2}\left(\psi_{f} i_{q}+\left(L_{d}-L_{q}\right) i_{d} i_{q}\right)
\end{gathered}
$$

where $v_{d}, v_{q}=d$ - and $q$-axis stator voltages; $i_{d}, i_{q}=d$ - and $q$ axis stator currents; $R=$ stator per phase resistance; $L_{d}, L_{q}=$ $d$ - and $q$-axis stator inductances; $J_{m}=$ moment of inertia of the motor and load; $B_{m}=$ friction coefficient of the motor; $P$ $=$ number of poles of the motor; $\omega_{r}=$ rotor speed in angular frequency; $p=$ differential operator $(=d / d t) ; \psi_{f}=$ rotor magnetic flux linking the stator; $T_{e}, T_{L}=$ electromagnetic and load torques; $J_{m}=$ moment of inertia of the motor and load.

\section{Flux-Weakening Algorithm}

The steady-state voltage equations are derived from (1)

$$
\begin{gathered}
v_{q}=R_{s} i_{q}+\omega_{r} L_{d} i_{d}+\omega_{r} \psi_{f}, \\
v_{d}=-\omega_{r} L_{q} i_{q}+R_{s} i_{d} .
\end{gathered}
$$

For a limiting case of constant power of zero torque, the $q$ axis current is zero; therefore, the above (4) becomes

$$
\begin{gathered}
v_{q}=\omega_{r} L_{d} i_{d}+\omega_{r} \psi_{f}, \\
v_{d}=-R_{s} i_{d} .
\end{gathered}
$$

Considering

$$
V_{s}^{2}=v_{d}^{2}+v_{q}^{2}
$$

one can find the maximum value of speed for the maximum available inverter (also stator) voltage $V_{s}$ from (5), and (6) as follows

$$
\omega_{r \max }=\frac{\sqrt{V_{s}^{2}-R_{s}^{2} i_{d}}}{\psi_{f}+i_{d} L_{d}} .
$$

The denominator of the above (7) must be positive giving condition of maximum stator current to be applied to counter the permanent magnet flux linkages as

$$
i_{d \max } \leq\left(-\frac{\psi_{f}}{L_{d}}\right) .
$$


Equations (7) and (8) are considered very important for real-time implementation because these expressions provide upper limiting values of speed and $d$-axis current for a given IPMSM. By considering stator resistance $R_{s}=0$, voltagelimited ellipse equation can also be derived from (4), and (7) as

$$
\left(\frac{i_{d}+\psi_{f} / L_{d}}{\left(V_{s} / \sqrt{2}\right) / \omega_{r} L_{d}}\right)^{2}+\left(\frac{i_{q}}{\left(V_{s} / \sqrt{2}\right) / \omega_{r} L_{q}}\right)^{2}=1
$$

Plots of $q$-axis versus $d$-axis currents are shown in Figure 1 for speed range $200 \mathrm{rad} / \mathrm{sec}$ to $850 \mathrm{rad} / \mathrm{sec}$ (base speed $188 \mathrm{rad} / \mathrm{sec}$ ) for a maximum inverter voltage of 250 volt.

Considering

$$
I_{s}=\sqrt{i_{d}^{2}+i_{q}^{2}}
$$

the expression of $d$-axis current can be derived from (5) as

$$
i_{d}=\frac{-L_{d} \psi_{f} \pm L_{q} \sqrt{\left[\left\{\left(L_{d}^{2}-L_{q}^{2}\right)\left(V_{s} / \omega_{r} L_{q}\right)^{2}-I_{s}\right\}+\psi_{f}^{2}\right]}}{L_{d}^{2}-L_{q}^{2}} .
$$

With the IPMSM data given in the appendix, the expression of $i_{d}$ in (11) has been simplified for the real-time implementation using curve fitting method for a working operating range of speed of $188 \mathrm{rad} / \mathrm{sec}$ (base speed) to $276 \mathrm{rad} / \mathrm{sec}$ (doubling base speed) as

$$
i_{d}=-0.000119 \omega_{r}^{2}-0.080316 \omega_{r}+10.5269 .
$$

Using (10), the expression for $q$-axis current $i_{q}$ has been obtained which is also simplified using curve fitting method and is given as

$$
i_{q}=-0.260375 i_{d}^{2}-0.244651 i_{d}+3.4422727 .
$$

Equations (12) and (13) are the key equations used for the flux-weakening control of IPMSM. Block diagram in Figure 2 shows the control scheme of the motor drive.

Using (12), the command $d$-axis current $i_{d}^{*}$ is computed first, subsequently reference $d$-axis current $i_{q}^{*}$ is calculated using (13). The command torque is obtained from a PI and fuzzy type speed controller. An estimated torque is calculated using (3), (12), and (13) and compared with the command torque. As long as the command torque is greater than the estimated torque, (12), and (13) are used to compute the three phase reference currents with the vector rotator. If the command torque is less than estimated torque, reference $q$ axis current is calculated using the command torque rather than the estimated torque. The speed error is processed by the fuzzy controller to generate the torque-producing current component command $i_{q}^{*}(n)$. The complete design of fuzzy controller is shown in Section 4. The hysteresis current controller compares the reference three phase currents with actual currents and generates base signals for the transistorized inverters.

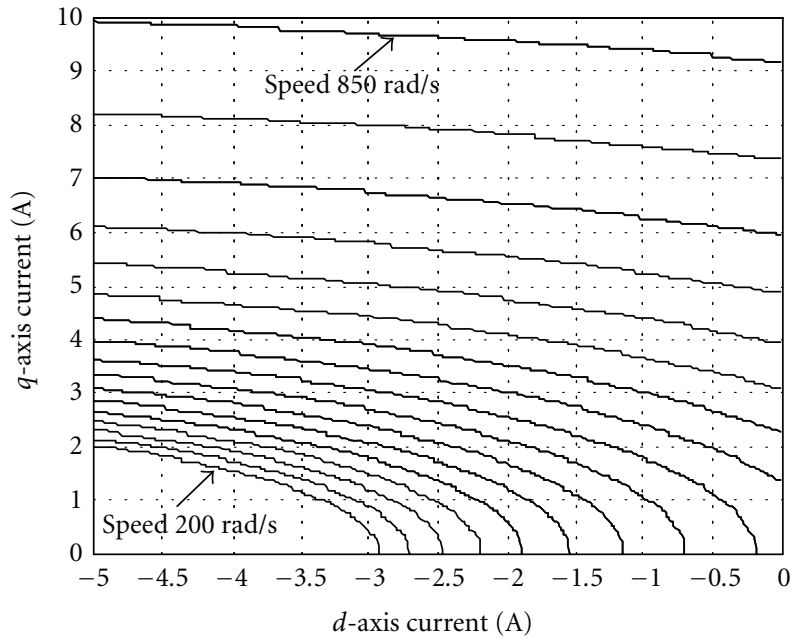

FIGURE 1: Voltage-limited ellipses of IPMSM for flux-weakening method of speed control.

\section{Design of Simplified FLC for IPMSM}

In this work, the fuzzy logic controller is based on the fuzzy set and fuzzy logic theory introduced by Zadeh, with the vector control techniques incorporated with the FLC to obtain the highest torque sensitivity of the IPMSM drive. The vector control technique is formulated within the $d-q$ synchronously rotating rotor reference frame. The complexity of the control arises due to the nonlinear nature of the torque expressed by (3). Moreover, $L_{d}$ and $L_{q}$ undergo significant variations at different steady-state and dynamic loading condition [2]. The dynamic model of the IPMSM may be rewritten from (1) to (3) as [16-18],

$$
\begin{aligned}
& p i_{q}=\frac{\left(v_{q}-R i_{q}-K_{b} \omega_{r}\right)}{L_{q}}, \\
& p \omega_{r}=\frac{\left(T_{e}-T_{L}-B_{m} \omega_{r}\right)}{J_{m}},
\end{aligned}
$$

where $K_{b}=p \Psi_{f}$. As the FLC can handle any nonlinearity, one can consider the load as unknown nonlinear mechanical characteristics. The load can be modeled using the following equation as [4]:

$$
T_{L}=A \omega_{r}^{2}+B \omega_{r}+C,
$$

where $A, B$, and $C$ are arbitrary constants. To make the control task easier, the equation of an IPMSM expressed as a single input nd single output system by combining (15) and (16) in continuous time domain form as [16-18],

$$
J_{m} \frac{d \omega_{r}}{d t}=T_{e}-\left(B_{m}+B\right) \omega_{r}-A \omega_{r}^{2}-C .
$$

A small incremental change $\Delta T_{e}$ of the electrical torque $T_{e}$ results in a corresponding change $\Delta \omega_{r}$ of the speed $\omega_{r}$, then (17) can be rewritten as

$$
J_{m} \frac{d\left(\Delta \omega_{r}\right)}{d t}=\Delta T_{e}-\left(B_{m}+B\right)\left(\Delta \omega_{r}\right)-A\left(\Delta \omega_{r}^{2}\right) .
$$




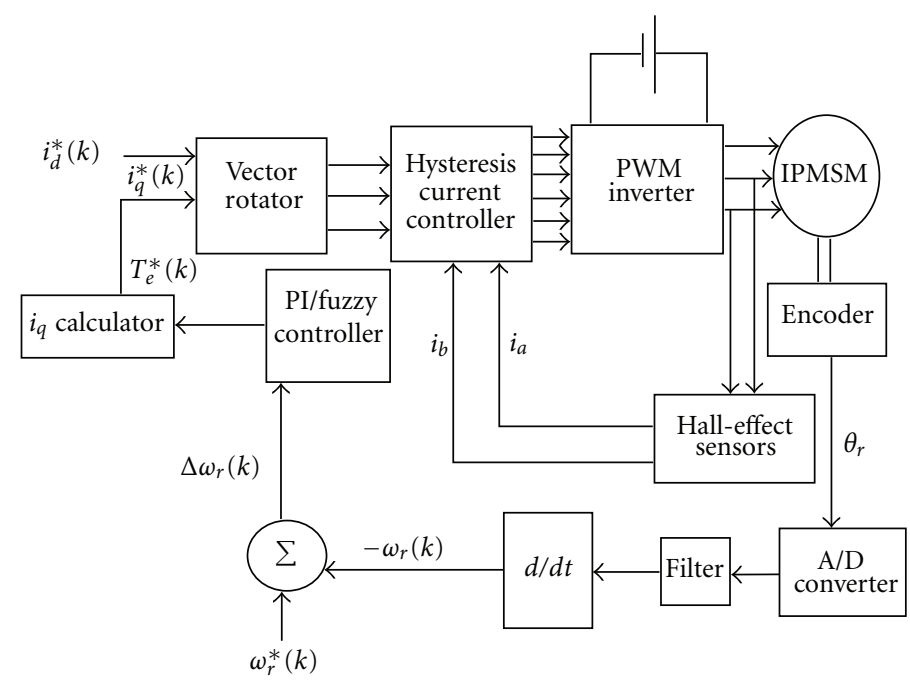

Figure 2: Block diagram of flux-weakening speed control of IPMSM drive.

By replacing all the continuous quantities of (18) by their finite differences, the discrete time signal model of the simplified IPMSM with nonlinear load can be given as [1618]

$$
\Delta T_{e}(n)=\frac{-J_{m}}{t_{s}} \Delta e(n)+\left(B_{m}+B\right) \Delta \omega_{r}(n)+A\left\{\Delta \omega_{r}(n)\right\}^{2} .
$$

Hence,

$$
T_{e}(n)=\int_{\text {discrete }} \Delta T_{e}(n)=f\left(\Delta e(n), \Delta \omega_{r}(n)\right),
$$

where $\Delta e(n)=\Delta \omega_{r}(n)-\Delta \omega_{r}(n-1)$ is the change of speed error, $\Delta \omega_{r}(n)=\omega_{r}^{*}(n)-\omega_{r}(n)$ is the present sample of speed error, $\Delta \omega_{r}(n-1)$ is the past sample of speed error, $\omega_{r}(n)$ is the present sample of actual speed, $\omega_{r}^{*}(n)$ is the present sample of command speed, $t_{s}$ is the sampling time interval, and $f$ denotes the nonlinear function. Thus, the purpose of using the FLC is to map the nonlinear functional relationship between electrical torque $T_{e}$ and rotor speed $\omega_{r}$. From this command torque $T_{e},(12)$ and (13) are used to calculate the necessary $q$ - and $d$-axis currents to produce the rotor speed $\omega_{r}$. In real time, the motor position information and output of the simplified FLC in terms of the command $q$-axis and $d$-axis currents $i_{q}^{*}$ and $i_{d}^{*}$ are used to get the motor command phase current $i_{a}^{*}, i_{b}^{*}$, and $i_{c}^{*}$ by using Park's transformation.

The model of the IPMSM expressed by (20) defines the input and output linguistic variables for the FLC of the IPMSM drive. According to (20), the input of the proposed FLC is the present sample of speed error and the change of speed error, which is the difference between present and past sample of speed errors. However, it has been observed that the effect of the inclusion of the change of speed error on the motor speed response is negligible and does not produce an improvement in motor drive performance in measure with the necessary increase in computational burden as compared to when it is omitted. The omission of the $\Delta e(n)$ term produces an FLC-based drive with acceptably responsive and
TABLE 1: Fuzzy rule-based matrix.

\begin{tabular}{llllll}
\hline$\Delta \omega_{r}$ & $\mathrm{PH}$ & $\mathrm{PL}$ & $\mathrm{NL}$ & $\mathrm{NH}$ & $\mathrm{ZE}$ \\
\hline$T_{e}$ & $\mathrm{PH}$ & $\mathrm{PL}$ & $\mathrm{NL}$ & $\mathrm{NH}$ & $\mathrm{NC}$ \\
\hline
\end{tabular}

accurate tracking of the command speed. Thus, the input vectors of the FLC can be reduced to only $\Delta \omega_{r}(n)$, producing a much simplified FLC as compared to input vectors of $\Delta \omega_{r}(n)$ and $\Delta e(n)$ with the nonsimplified system. This simplification reduces computational burden and lowers the computer power required to implement the FLC scheme in real-time. Thus, this simplified FLC is a significant factor for real time implementation of the laboratory IPMSM drive system [17].

The block diagram of the proposed FLC-based IPMSM drive incorporating field-weakening method is shown in Figure 2. Next, scaling factors $K_{w}$ and $K_{i}$ are chosen for fuzzification and obtaining the appropriate actual command current. The factor $K_{w}$ is chosen so that the normalized value of speed error $\Delta \omega_{r}$ remains within the limit of \pm 1 . The factor $K_{i}$ is chosen so that the rated current $i$ can be produced by the controller for rated conditions. In this paper, the constants are taken as $K_{w}=\omega_{r}^{*}$ (command speed) and $K_{i}=10$ in order to get the optimum drive performance. After selecting the scaling factors, the next step is to choose the membership functions of $\Delta \omega_{r}$ and $i_{q n}^{*}$, which form an important element of the FLC. The membership functions used for the input and output fuzzy sets are shown in Figure 3. The trapezoidal functions are used as membership functions for all the fuzzy sets except the fuzzy set ZE (zero) of the input vectors. The triangular membership functions are used for the fuzzy set $\mathrm{ZE}$ of the input vectors and all the fuzzy sets of the output vector. The trapezoidal and triangular functions are used to reduce the computation for online implementation. The rules used for the proposed FLC algorithm are as follows

(i) if $\Delta \omega_{r}$ is $\mathrm{PH}$ (positive high), $T_{e}$ is $\mathrm{PH}$ (positive high);

(ii) if $\Delta \omega_{r}$ is PL (positive low), $T_{e}$ is PM (positive medium); 


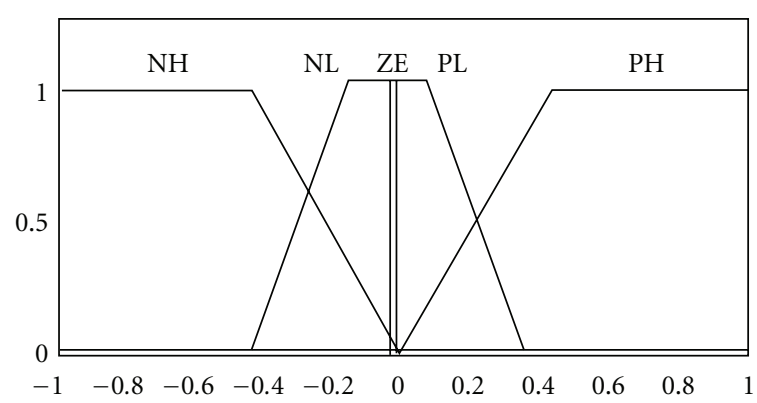

(a)

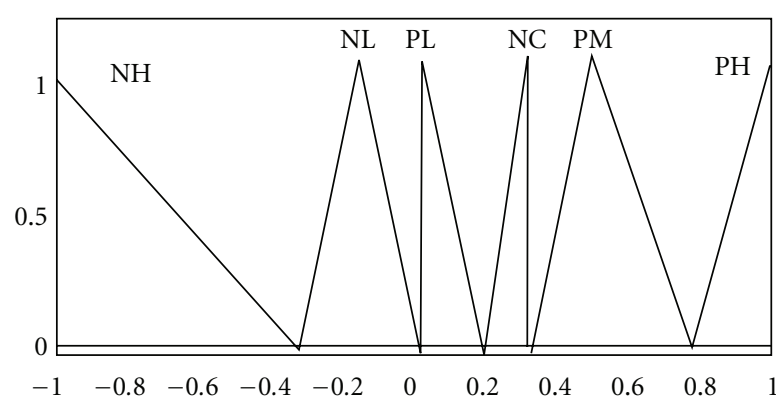

(b)

Figure 3: Member functions for (a) speed error $\Delta \omega_{r n}$ and (b) command torque $T_{e}^{*}$.

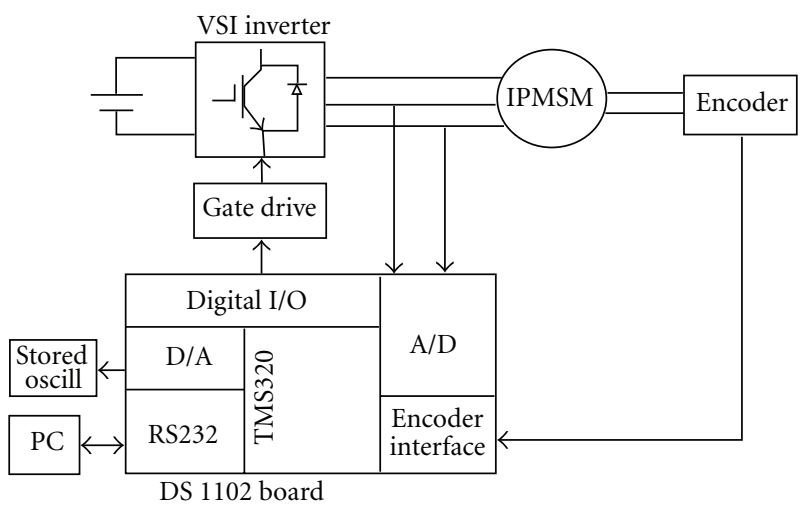

FIgURE 4: Hardware schematic for real-time implementation.

(iii) if $\Delta \omega_{r}$ is NL (negative low), $T_{e}$ is NL (negative low);

(iv) if $\Delta \omega_{r}$ is $\mathrm{NH}$ (negative high), $T_{e}$ is $\mathrm{NH}$ (negative high).

Mathematically, the trapezoidal membership function can be defined as

$$
\text { Trapezoidal : } f(x ; a, b, c, d)= \begin{cases}0 & x \leq a \\ \frac{x-a}{b-a} & a \leq x \leq b \\ 1 & b \leq x \leq c \\ \frac{d-x}{d-c} & c \leq x \leq d \\ 0 & x \geq d .\end{cases}
$$

The triangular membership function can be obtained from the trapezoidal function by setting $b=c$. The rules used for the proposed FLC algorithm are shown in Table 1. Based on the rules, the fuzzy-rule-based matrix is shown above. For this study, Mamdani-type fuzzy inference is used [15]. The values of the constants, membership functions, fuzzy sets for the input/output variables, and the rules used in this study are selected by trial and error to obtain the optimum drive performance. In this study, the center of gravity defuzzification is used. The output function is given as

$$
i=\frac{\sum_{k=1}^{N} i \mu_{C(k)}(i)}{\sum_{k=1}^{N} \mu_{C(k)}(i)_{d}},
$$

TABLE 2: Machine parameters.

\begin{tabular}{lc}
\hline Motor rated power & 3-phase, $1 \mathrm{hp}$ \\
\hline Rated voltage & $250 \mathrm{~V}$ \\
Rated current & $3 \mathrm{~A}$ \\
Rated frequency & $60 \mathrm{~Hz}$ \\
Pole pair number $(P)$ & 2 \\
$d$-axis inductance, $L_{d}$ & $42.44 \mathrm{mH}$ \\
$q$-axis inductance, $L_{q}$ & $79.57 \mathrm{mH}$ \\
Stator resistance, $R$ & $1.93 \Omega$ \\
Motor inertia, $J_{m}$ & $0.003 \mathrm{~kg} \mathrm{~m}{ }^{2}$ \\
Friction coefficient, $B_{m}$ & $0.001 \mathrm{Nm} / \mathrm{rad} / \mathrm{sec}$ \\
Magnetic flux constant, $\psi_{f}$ & $0.311 \mathrm{volts} / \mathrm{rad} / \mathrm{sec}$ \\
\hline
\end{tabular}

where $N$ is the total number of rules and $\mu_{C(k)}(i)$ denotes the output membership grade for the $k$ th rule with the output subset $C$.

\section{Laboratory Implementation of PI-Based Flux-Weakening IPMSM Rive}

The complete IPMSM drive system has been implemented in the laboratory for a 1-hp laboratory IPMSM using DSPACE DSP (digital signal processing) controller board [8]. The complete hardware schematic for real-time implementation of the IPMSM drive is shown in Figure 4. Machine parameters are given in the Appendix. The DSP board is installed in a $\mathrm{PC}$ with uninterrupted communication capabilities through dual-port memory. The DSP has been supplemented by a set of on-board peripherals used in digital control systems, such as A/D (analog to digital), D/A (digital to analog) converters, and incremental encoder interfaces. The DS 1102 is also equipped with a TI TMS320P14, 16-bit microcontroller DSP that acts as a slave processor and is used for some special purposes.

In this work, slave processor is used for digital I/O configuration. The actual motor currents are measured by the Hall-effect sensors which have good frequency response and fed to the DSP board through A/D converter. As the motor neutral is isolated, only two-phase currents are fed back, and the other phase current is calculated from them. Three phase 


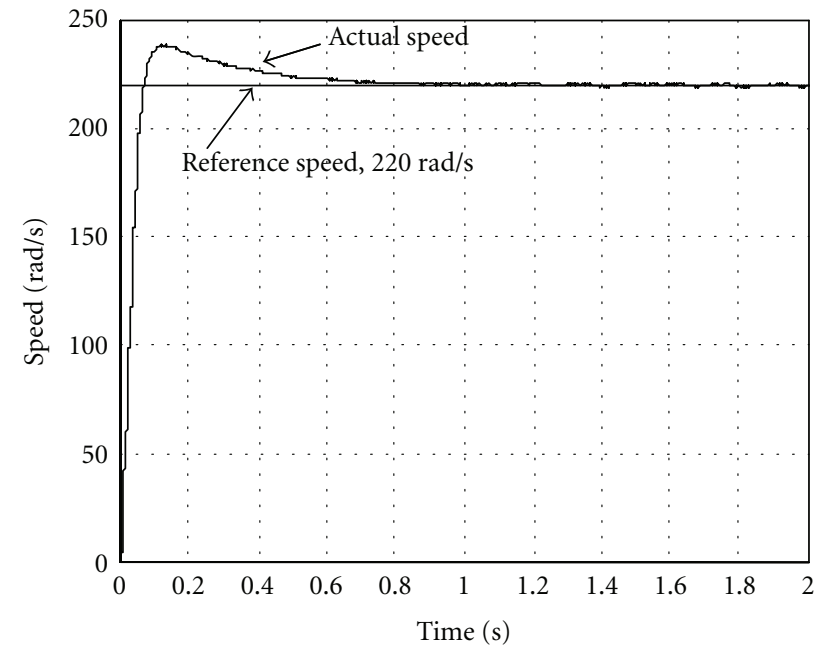

(a)

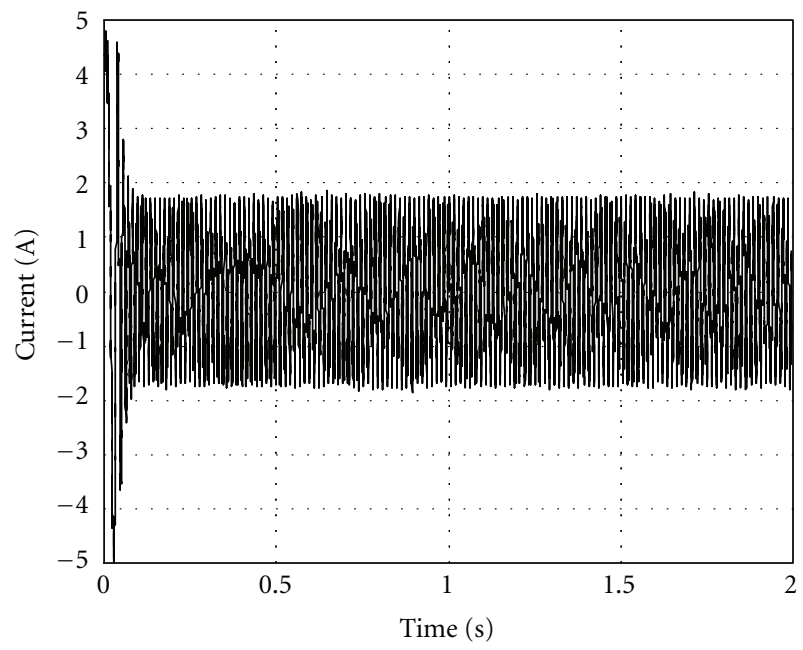

(b)

FIGURE 5: (a) Simulated speed of IPMSM drive for flux-weakening control with reference speed $220 \mathrm{rad} / \mathrm{s}$ using PI controller. (b) Simulated current of IPMSM drive for flux-weakening control with reference speed $220 \mathrm{rad} / \mathrm{s}$ using PI controller.

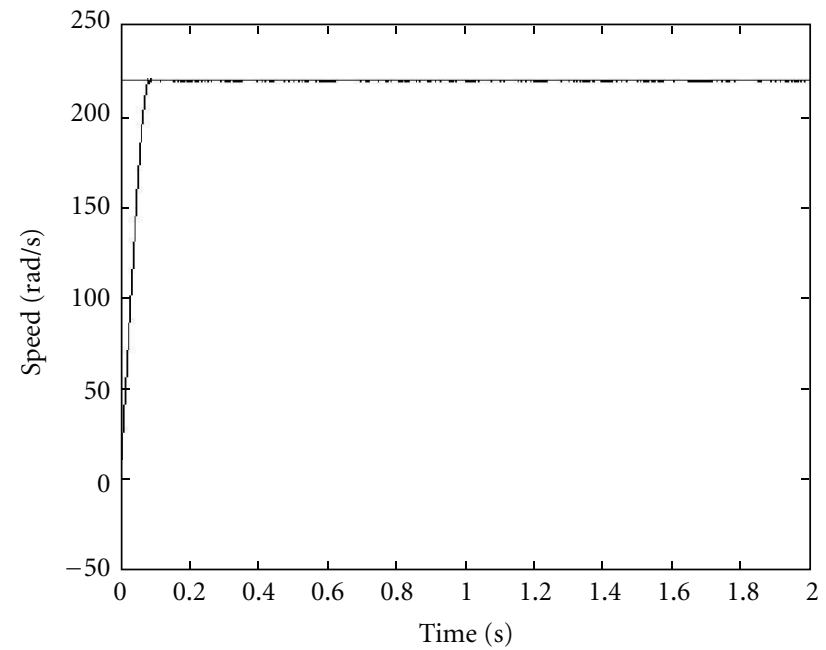

(a)

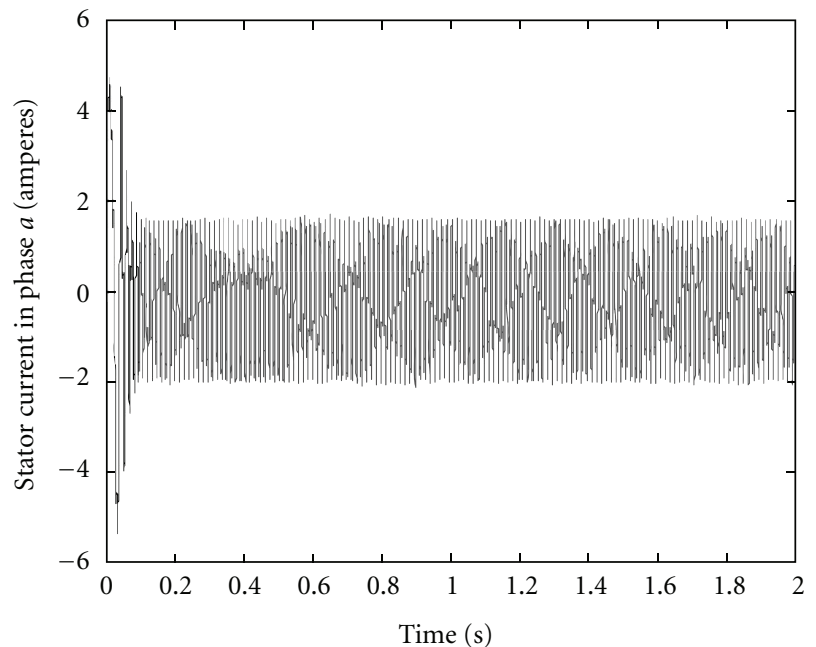

(b)

FIGURE 6: (a) Simulated speed of IPMSM drive for flux-weakening control with reference speed $220 \mathrm{rad} / \mathrm{s}$ using fuzzy controller. (b) Simulated current of IPMSM drive for flux-weakening control with reference speed $220 \mathrm{rad} / \mathrm{sec}$ using fuzzy controller.

reference currents are generated utilizing reference $q$ - and $d$-axis currents and rotor position angle obtained through encoder mounted on the shaft of the motor. Computed three phase reference currents are converted to upper and lower hysteresis by adding and subtracting a reselected band. Hysteresis currents are compared with actual motor currents, and PWM (pulse-width modulation) base drive signals are generated. All computations for generating reference currents and consequently base drive signals for the inverter are done by developing a program in ANSI C programming language. The program is compiled using Texas Instrument C compiler and downloaded to the DSP controller board. The sampling frequency for experimental implementation of the proposed drive is $10 \mathrm{kHz}$.

\section{Results and Discussions}

The performance of FLC-based flux-weakening controlbased IPMSM drive has been evaluated by computer simulation. The speed and current responses are observed under different operating conditions such as various command speeds, sudden application of load, step change in command speed, and at different loading conditions. Some of the sample results are presented in this paper. Figures 5 and 6 show the simulated starting performance of the drive with PI- and FLC-based drive systems, respectively, for fluxweakening control-based IPMSM drive system with reference speed of $220 \mathrm{rad} / \mathrm{sec}$ at a load of $2 \mathrm{~N}-\mathrm{m}$. Although the PI controller is tuned to give an optimum response, the fuzzy 


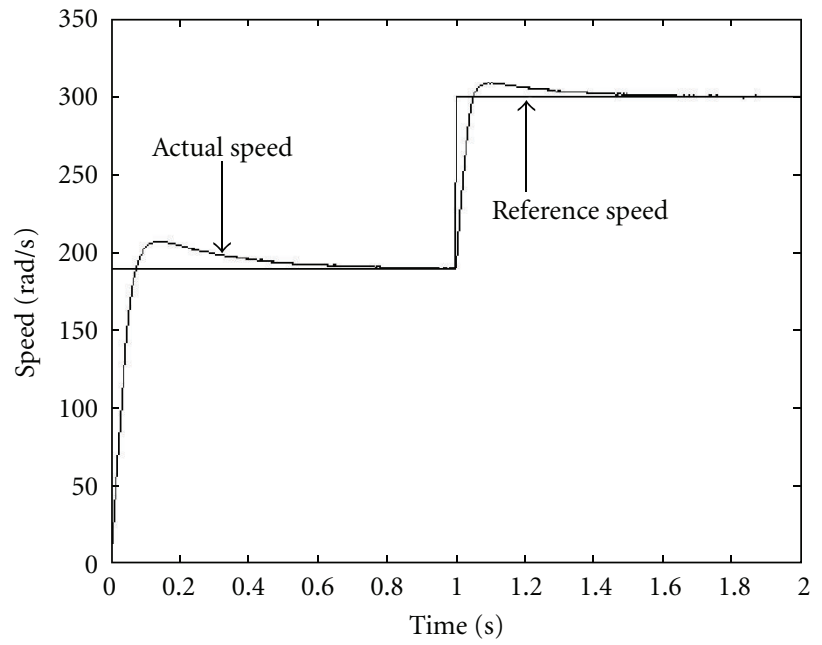

(a)

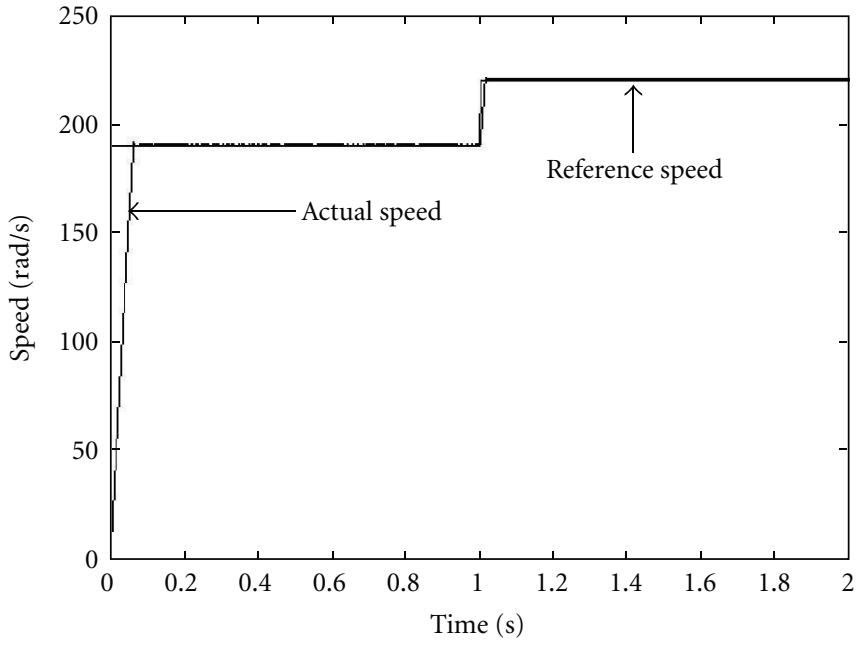

(b)

FIGURE 7: (a) Simulated speed of IPMSM drive for flux-weakening control due to step change of reference speed using PI controller. (b) Simulated speed of IPMSM drive for flux-weakening control due to step change of reference speed using fuzzy controller.

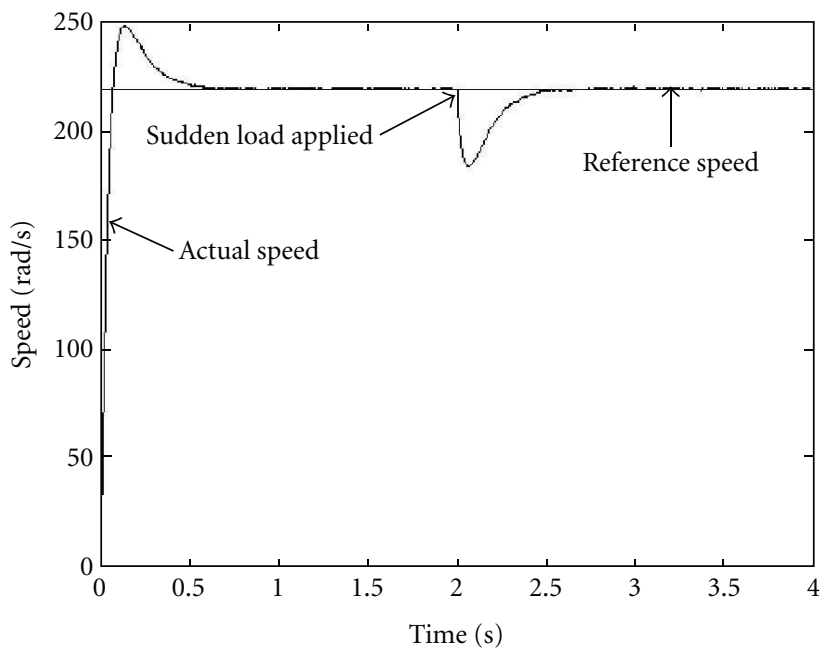

(a)

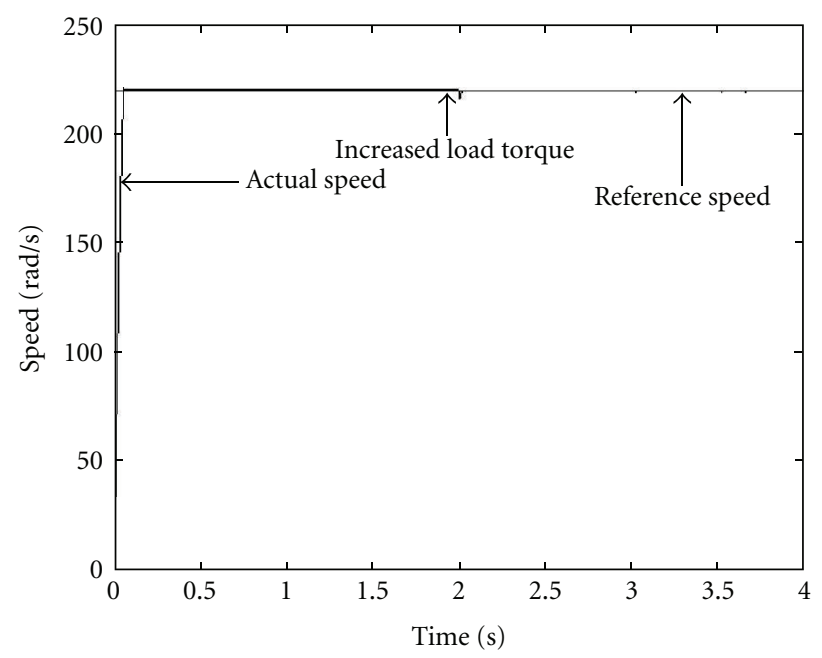

(b)

FIGURE 8: (a) Simulated speed of IPMSM drive for flux-weakening control with reference speed $220 \mathrm{rad} / \mathrm{sec}$ using PI controller with sudden load applied. (b) Simulated speed of IPMSM drive for flux-weakening control with reference speed $220 \mathrm{rad} / \mathrm{sec}$ using fuzzy controller with sudden load applied.

controller yielded better performances in terms of faster response time without any overshoot and lower starting current.

Figures 7(a) and 7(b) show speed responses of the drive system using PI and FLC, respectively, with a step change in the reference speed. It is evident from Figures 7(a) and 7 (b) that the proposed FLC-based drive system can follow the command speed without any overshoot and steady-state error. Thus, the FLC-based drive system is not affected by the sudden change of command speed. So, a good tracking has been achieved for the FLC, whereas the PI-controller-based drive system is affected with sudden change in command speed. Figures $8(\mathrm{a})$ and $8(\mathrm{~b})$ show speed responses of the drive system using PI and FLC, respectively, with a sudden change in loading torque. The motor was started with no load, and this value was increased to $2 \mathrm{~N}$-m after two seconds causing a drop in motor speed. The PI took less than 0.5 second, and fuzzy logic controller took negligible time to respond to this change in torque for operating the motor at the command speed. Figures 9(a) and 9(b) show simulated current response, respectively, for PI, and fuzzy controllerbased IPMSM drive system with sudden application of a load of $2 \mathrm{~N}-\mathrm{m}$. Figures $10(\mathrm{a})$ and 10(b) show experimental speed and steady-state current response, respectively, for PIbased flux-weakening control-based IPMSM drive system with reference speed at a load of $2 \mathrm{~N}-\mathrm{m}$. 


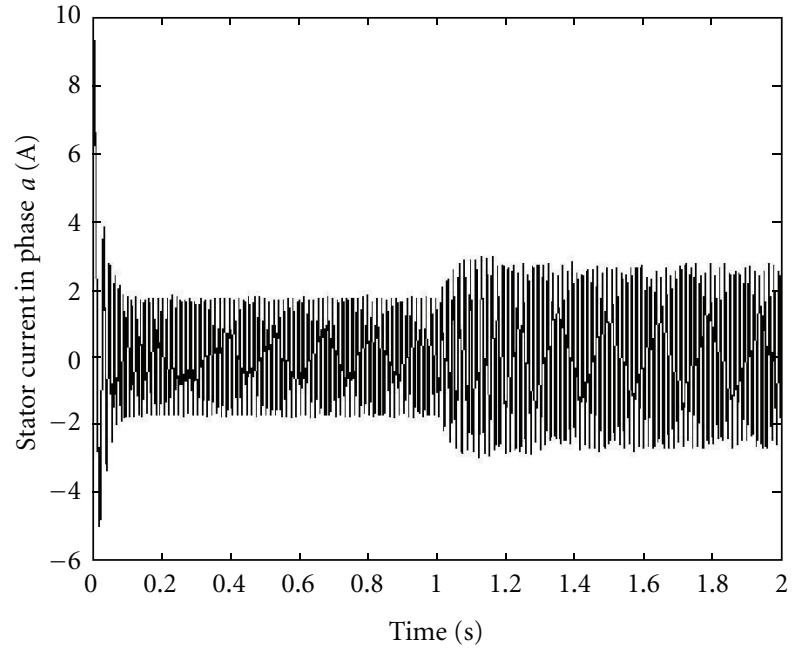

(a)

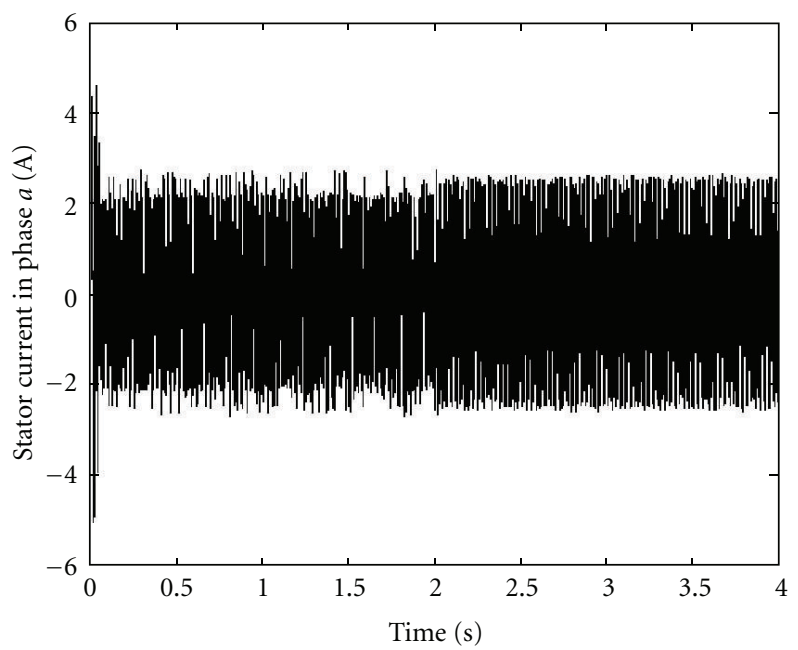

(b)

Figure 9: (a) Simulated current of IPMSM drive for flux-weakening control with reference speed $220 \mathrm{rad} / \mathrm{sec}$ using fuzzy controller with sudden load applied. (b) Simulated current of IPMSM drive for flux-weakening control with reference speed $220 \mathrm{rad} / \mathrm{sec}$ using fuzzy controller with sudden load applied.

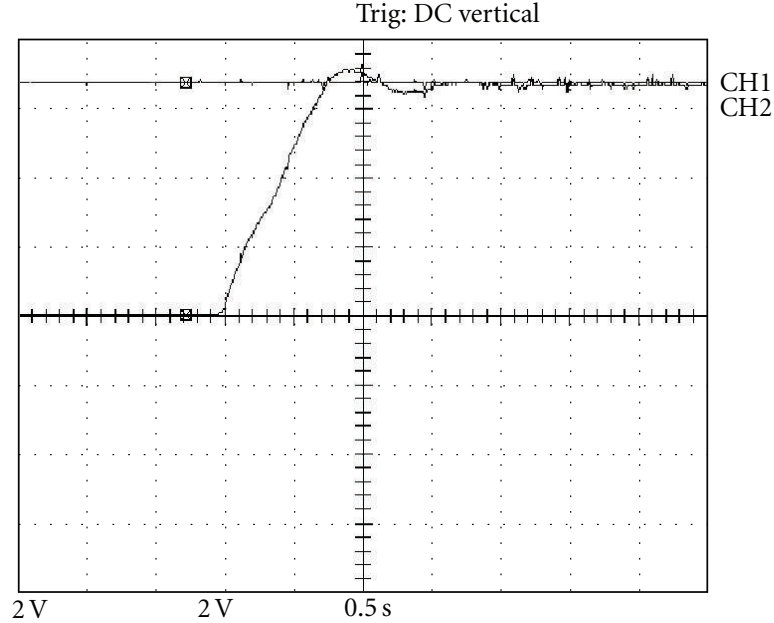

(a)

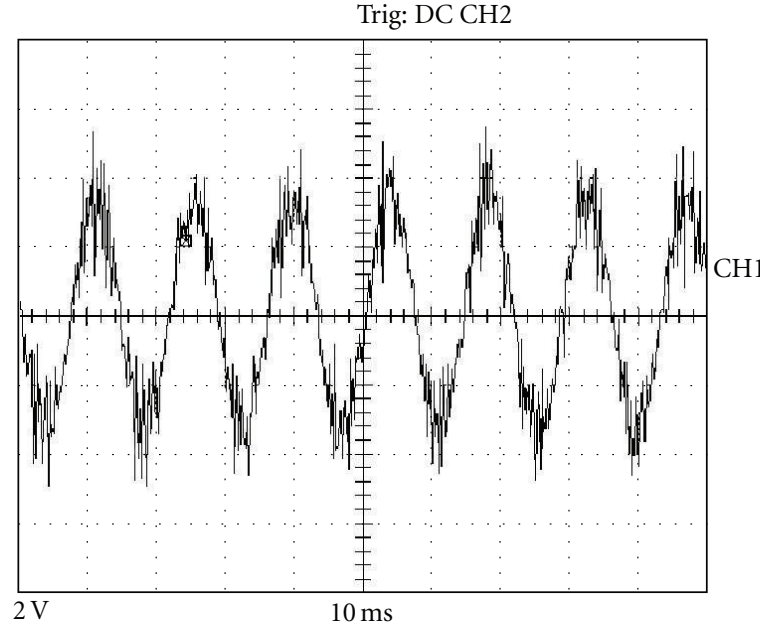

(b)

Figure 10: (a) Experimental speed of IPMSM drive for flux-weakening control with reference speed $220 \mathrm{rad} / \mathrm{sec}$ using PI controller ( $Y$ axis: $1 \mathrm{div}=65 \mathrm{rad} / \mathrm{sec}$ ). (b) Experimental steady-state current response of IPMSM drive for flux-weakening control with reference speed $220 \mathrm{rad} / \mathrm{sec}$ using PI controller ( $Y$-axis: 1 div $=2 \mathrm{~A}$ ).

\section{Conclusions}

In this paper, a new approach for fuzzy logic-based algorithm of flux-weakening method has been applied for the speed control of IPMSM drive above the base speed. In this work, relatively simpler expressions of $d$ - and $q$-axis currents have been derived and incorporated in the IPMSM drive system. Simplified fuzzy controller for the IPMSM has also been designed and implemented through simulation. The IPMSM drive system is efficient enough to operate in no load and loading condition. Derived equation of voltage-limited ellipse, which has been plotted in Figure 1, may dictate a new approach of flux-weakening method for an optimum value of stator current, which will provide better performance in terms of efficiency. From the obtained results, it is obvious that the FLC-based IPMSM drive has been found superior to the conventional PI-controller based-system.

\section{Appendix}

See Table 2.

\section{References}

[1] R. Krishnan, "Selection criteria for servo motor drives," IEEE Transactions on Industry Applications, vol. 23, no. 2, pp. 270275, 1987. 
[2] M. A. Rahman and P. Zhou, "Field circuit analysis of brushless permanent magnet synchronous motors," IEEE Transactions on Industry Electronics, vol. 43, no. 2, pp. 256-267, 1996.

[3] M. F. Rahman, L. Zhong, and K. W. Lim, "A direct torquecontrolled interior permanent magnet synchronous motor drive incorporating field weakening," IEEE Transactions on Industry Applications, vol. 34, no. 6, pp. 1246-1253, 1998.

[4] M. R. Emami, I. B. Turksen, and A. A. Goldenberg, "Development of a systematic methodology of fuzzy logic modeling," IEEE Transactions on Fuzzy Systems, vol. 6, no. 3, pp. 346-361, 1998.

[5] S. Y. Yi and M. J. Chung, "Robustness of fuzzy logic control for an uncertain dynamic system," IEEE Transactions on Fuzzy Systems, vol. 6, no. 2, pp. 216-225, 1998.

[6] K. Erenay, I. Ciprut, L. Tezduyar, and Y. Istefanopulos, "Application of fuzzy algorithms to the speed control of washing machines with brushless Dc motors," in Proceedings of the International Conference on Electrical Machines, pp. 12311236, Istanbul, Turkey, 1998.

[7] E. Cerruto, A. Consoli, A. Raciti, and A. Testa, "Fuzzy adaptive vector control of induction motor drives," IEEE Transactions on Power Electronics, vol. 12, no. 6, pp. 1028-1039, 1997.

[8] S. Bolognani and M. Zigliotto, "Fuzzy logic control of a switched reluctance motor drive," IEEE Transactions on Industry Applications, vol. 32, no. 5, pp. 1063-1068, 1996.

[9] B. Singh, V. K. Sharma, and S. S. Murthy, "Performance analysis of adaptive fuzzy logic controller for switched reluctance motor drive system," in Proceedings of the IEEE/IAS Annual Meeting Conference Record, pp. 571-579, October 1998.

[10] M. Tursini, E. Chiricozzi, and R. Petrella, "Feedforward fluxweakening control of surface-mounted permanent-magnet synchronous motors accounting for resistive voltage drop," IEEE Transactions on Power Electronics, vol. 57, no. 1, pp. 440 $448,2010$.

[11] X. Cao and L. Fan, "A novel flux-weakening control scheme based on the fuzzy logic of PMSM drive," in Proceedings of the IEEE International Conference on Mechatronics and Automation (ICMA '09), pp. 1228-1232, Changchun, China, August 2009.

[12] X. Cao and L. Fan, "Flux-weakening control scheme based on the fuzzy logic of pmsm drive for hybrid electric vehicle," in Proceedings of the International Conference on Control, Automation and Systems Engineering, pp. 287-290, July 2009.

[13] B. K. Bose, "High-performance inverter-fed drive system of an interior permanent magnet synchronous machine," IEEE Transactions on Industry Applications, vol. 24, no. 6, pp. 987997, 1988.

[14] S. Morimoto, M. Sanada, and Y. Takeda, "Wide-speed operation of interior permanent magnet synchronous motors with high-performance current regulator," IEEE Transactions on Industry Applications, vol. 30, no. 4, pp. 920-926, 1994.

[15] N. N. Uddin and M. A. Rahman, "High-speed control of IPMSM drives using improved fuzzy logic algorithms," IEEE Transactions on Industrial Electronics, vol. 54, no. 1, pp. 190199, 2007.

[16] C. B. Butt, M. A. Hoque, and M. A. Rahman, "Simplified fuzzy-logic-based MTPA speed control of IPMSM drive," IEEE Transactions on Industrial Electronics, vol. 40, no. 6, pp. 1529$1535,2004$.

[17] C. Butt, M. A. Hoque, and M. A. Rahman, "Simplified Fuzzy Logic Based MTPA Speed Control of IPMSM Drive," in Proceedings of the 38th IEEE Industry Application Society Annual Meeting, pp. 499-506, Salt Lake City, Utah, USA, October 2003.
[18] C. Butt, M. A. Hoque, and M. A. Rahman, "Limitations simplified fuzzy-Logic controller for IPM motor drive," in Proceedings of the 38th IEEE Industry Application Society Annual Meeting, pp. 499-506, Salt Lake City, Utah, USA, October 2003. 

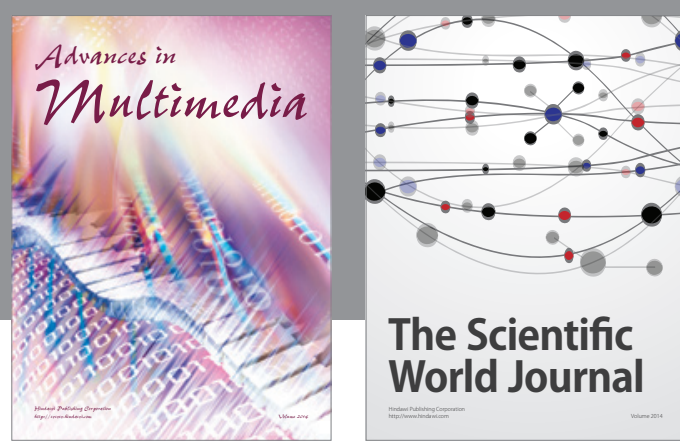

The Scientific World Journal
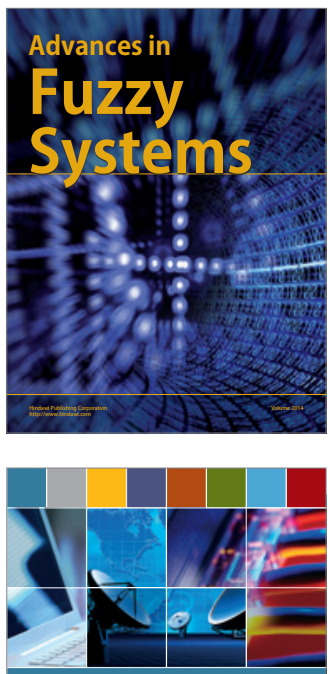

Computer Networks and Communications
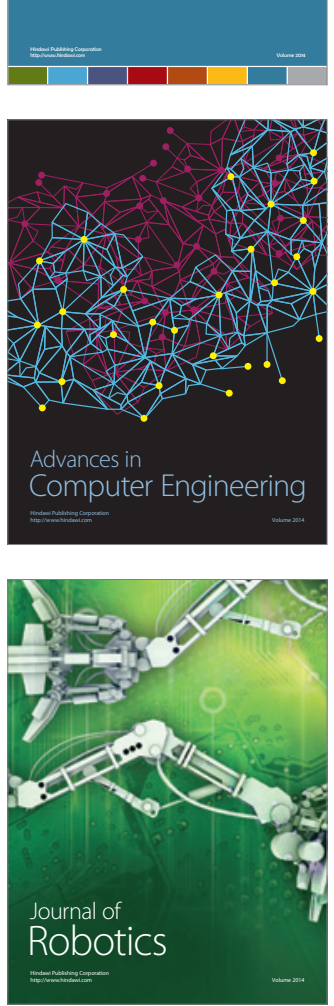
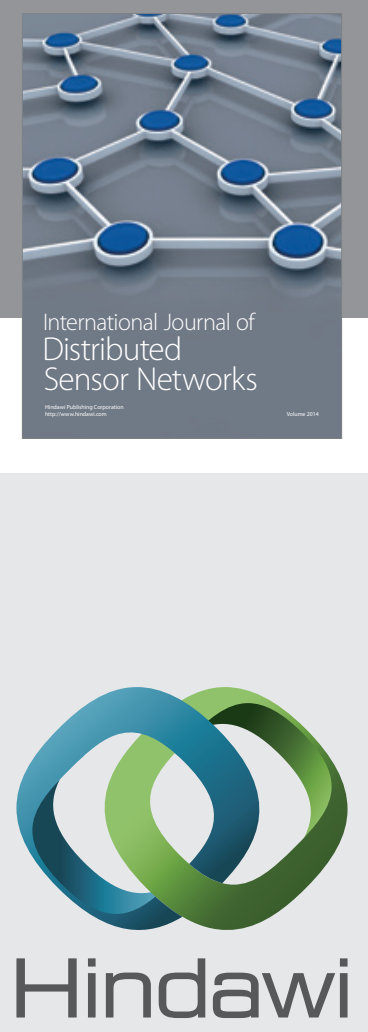

Submit your manuscripts at

http://www.hindawi.com
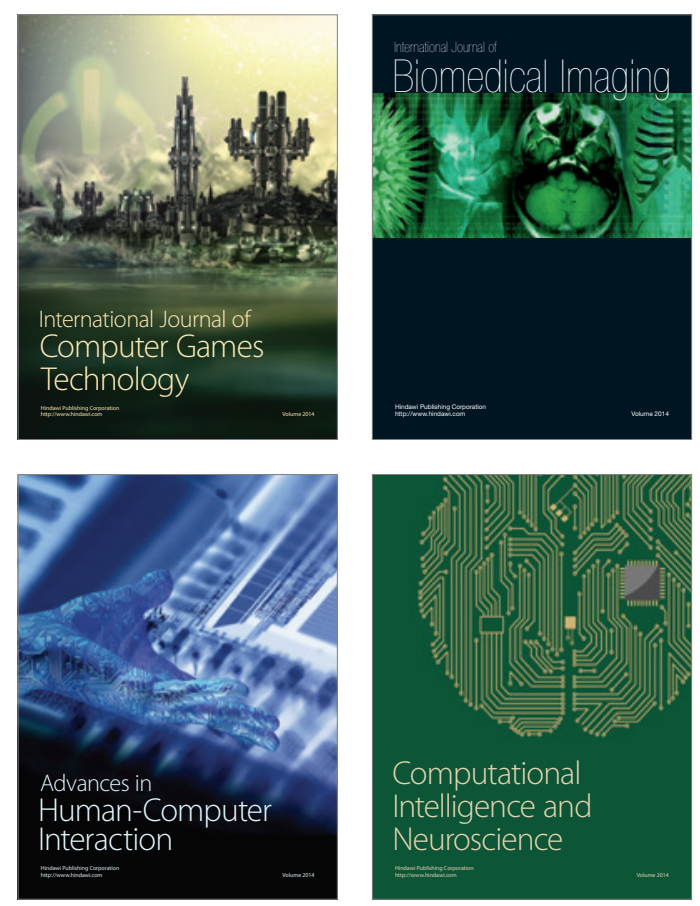
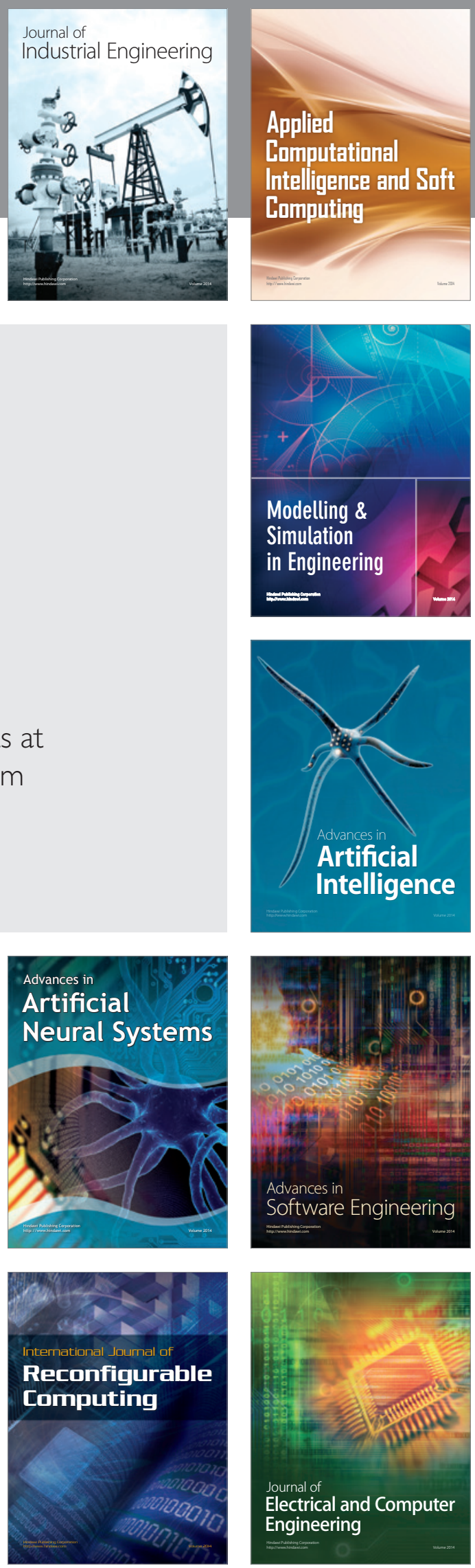